\title{
ESTADO E EDITORAS PRIVADAS NO BRASIL: O PAPEL E O PERFIL DOS EDITORES DE LIVROS DIDÁTICOS (1970-1990)
}

\author{
Décio GatTi Júnior
}

\begin{abstract}
RESUMO: Trata-se da comunicação de resultados de investigação no campo da história das disciplinas escolares, com foco no papel e no perfil dos editores de livros didáticos de história brasileiros que atuaram entre as décadas de 1970 e 1990 . Partiu-se da constatação de que boa parte das grandes editoras do final da década de 1990 era ligada à produção de livros didáticos, sendo empresas que tinham iniciado suas atividades em meados da década de 1970. Para subsidiar a análise foram consultados tanto a bibliografia e documentação pertinente quanto os depoimentos de editores brasileiros. Ao mesmo tempo em que se operava a passagem de uma forma de produção quase artesanal para uma produção industrial, vivenciou-se um processo de melhoria da qualidade tanto dos conteúdos, quanto da edição, o que significava a disponibilização de um material mais adequado para a população, seja por meio da política distributivista operada pelo Estado, seja por meio da aquisição nas livrarias pela população.
\end{abstract}

Palavras-chave: Livro didático. Editores. Ensino de história.

The State and PRIVATE PUblishing houses in Brazil: THE ROLE AND PROFILE OF TEXTBOOK PUBLISHERS (1970-1990)

ABSTRACT: This paper presents the results of a research in the field of the history of school disciplines, focusing on the role and profile of the Brazilian publishers of History textbooks from the 1970s to the 1990s. The study first verified that, at the end of the 1990s,

* Doutor em Educação pela Pontifícia Universidade Católica de São Paulo (PUC-SP), professor da Faculdade de Educação da Universidade Federal de Uberlândia (UFU) e membro da ANPEd, ANPUH e sócio-fundador da Sociedade Brasileira de História da Educação (sBHE). E-mail: degatti@ufu.br

Disponível em <http://www.cedes.unicamp.br> 
Estado e editoras privadas no Brasil: o papel e o perfil dos editores de livros didáticos...

many of the large publishing houses were connected with the production of textbooks and had begun their activity in the 1970s. To complement this analysis, the pertinent bibliography and documentation as well as the testimony of Brazilian publishers was consulted. At the same time as a shift from an almost handcrafted form of production to industrialized production occurred, there was a process of improvement in both quality of content and of publication. This meant the availability of more adequate material for the population either through the distributional policies carried out by the State or the direct purchase in bookstores.

Key words: Textbooks. Publishers. Teaching of history.

A

s políticas públicas para o setor editorial didático, entre as décadas de 1970 a 1990, não importando muito sob qual governo especificamente, foram marcadas pelo atendimento de interesses emanados do Estado, que era obrigado a conviver com um país que apresentava deficiências de toda ordem no campo educacional e que encontrava na distribuição de livros um paliativo extremamente útil, permitindo, simultaneamente, "agradar as editoras, garantir espaço na imprensa, facilitar 'negociatas' e promover políticos" (Carvalho, 1991, p. 16). Além disso, atendia às necessidades da indústria editorial, que funcionava em um mercado consumidor extremamente limitado, haja vista o pequeno número de leitores e a conseqüente mediocridade da quantidade de livros que eram ao menos comprados no país. ${ }^{1}$

Sem dúvida que a combinação destes interesses ocasionou o "afunilamento das funçôes do Estado", que se limitava ao empreendimento de uma "política distributivista de livros" sem, no entanto, ocupar-se dos problemas nevrálgicos do sistema educacional brasileiro (Carvalho, op. cit., p. 39-134).

Os editores, desse modo, precisavam que seus livros fossem bem aceitos no mercado escolar para que sua atividade editorial pudesse ter continuidade. Nesse sentido, era comum no final da década de 1990 a adaptação dos livros didáticos, em uma velocidade surpreendente, às modas didáticas e às mudanças curriculares estabelecidas pelos setores públicos afetos a área educacional.

No Brasil da década de 1970, o componente ideológico era forte no processo de definição da produção didática, especialmente dos conteúdos veiculados na disciplina História. Já no final da década de 1990, se- 
gundo os editores entrevistados, os lucros advindos da venda deste tipo de livro sobrepunham-se a quaisquer questôes ideológicas.

Nos Estados Unidos, os editores afirmam que "o que importa é a lucratividade e que (...) se existe alguma censura, é a que se refere à possível lucratividade" (Apple, 1994, p. 1995). Situação parecida era constantemente afirmada pelos representantes das editoras nacionais, tais como: "(...) o que importa não é a ideologia contida no livro e sim sua aceitação no mercado" (Munakata, 1997, p. 20).

Em uma abordagem mais técnica podem-se perceber as diversas etapas que envolvem a produção de livros didáticos. Etapas que aumentaram na mesma proporção em que cresceu a complexidade da produção didática no país. Nesse sentido, o depoimento do Sr. José Lino Fruet (gerente editorial da editora Saraiva) foi esclarecedor ao abordar o processo de edição, impressão e distribuição dos livros didáticos. Para ele,

(...) fazer livro, hoje [1997], é muito mais trabalhoso do que era 20 anos atrás. (...) Eu, como gerente, faço uma ponte entre os aspectos, digamos assim, filosóficos e a concretização prática. (...) A gente faz uma análise editorial do material, com todas as características editoriais. Se o material tem condição, a gente coloca para os pareceristas (...). Para isso, a gente procura professores que tenham experiência de sala de aula e formar um time com várias visões. (...) É normal que qualquer material tenha altos e baixos, tenha coisas lindas e outras que estão deixando a desejar. (...) A gente procura cercar, resolver todas essas questôes que foram colocadas, não impor para o autor, mas levantar os problemas para ele, que com a sua experiência, (...) vai solucionar de uma forma adequada. (...) Há casos em que existem três, quatro versões. (...) Depois, ele entra na produção editorial propriamente dita. É feito, principalmente, com os assistentes editoriais, que fazem o trabalho que chamamos de copidescagem. Não é uma simples revisão de português do material. Nós interferimos bastante em toda comunicação do material. (...) Isso, naturalmente, levando em consideração a matéria, a faixa etária, uma série de coisas. (...) Depois, segue a fase de produção de arte. $\mathrm{O}$ material vai para a composição. Nesse meio tempo a gente discute o projeto gráfico da obra. (...) Aí vai para a revisão. (...) Depois, seguem as etapas normais do processo editorial. Eles dão a primeira prova, a segunda, a terceira, as figuras, todas as ilustrações. O autor acompanha tudo isso e nós acompanhamos até a liberação da arte para fazer filme e impressão. Bem resumidamente é assim. ${ }^{2}$

Percebe-se, dessa forma, que os procedimentos editoriais do final da década de 1990 eram bastante sofisticados. As coleções de história, especi- 
Estado e editoras privadas no Brasil: o papel e o perfil dos editores de livros didáticos...

almente aquelas destinadas ao ensino fundamental eram cada vez melhor produzidas, com cores vivas, boxes, filigranas e, algumas, já incorporavam a substituição da encadernação, colada ou costurada, pela utilização da espiral plástica. A esta complexa estrutura de produção e seus respectivos custos financeiros deveriam ainda ser acrescentadas as despesas e o trabalho com armazenamento, mercadologia, propaganda, distribuição e vendas. De fato, divulgar e distribuir uma determinada coleção eram pré-condiçôes para posicioná-la bem no mercado de didáticos de então.

Segundo o depoimento do Sr. Antônio Alexandre Faccioli (diretor de didáticos da Saraiva), a divulgação exigia investimentos pesados das editoras: "em geral você tem que fazer oferta do livro. (...) Você tem que ter cacife. Não adianta só fazer a obra. Você tem que colocar dez, vinte, trinta mil exemplares da obra ou mais para serem distribuídas. Se você não vender adequadamente, você não vende nem o que você deu". ${ }^{3}$

Os editores eram os responsáveis pela execução das políticas editoriais destas empresas privadas dedicadas ao setor editorial. Apple (1994) analisou o perfil destes profissionais nos Estados Unidos e concluiu que suas ligações mais diretas não se estabelecem com os autores ou com os conteúdos veiculados por seus produtos, mas sim com as demandas do mercado consumidor. Para corroborar esta afirmação, evidenciou o fato de que $75 \%$ dos editores de livros escolares naquele país eram provenientes do setor de vendas das editoras, ou seja, conheciam mais as condiçôes de comercialização de livros que outra etapa produtiva (Apple, op. cit., p. 9-12). No caso dos editores brasileiros entrevistados durante a pesquisa que originou este texto, o perfil dos editores era, na época, bastante diferente daquele apresentado nos Estados Unidos.

\section{Formação acadêmica e itinerário profissional dos editores}

Por meio das entrevistas realizadas em 1997 foi possível levantar informações sobre a formação dos editores. O Sr. Antônio Alexandre Faccioli, da Saraiva, era formado em Letras. Segundo seu relato, só havia cursado a graduação, na década de 1970. Porém, destacou que sua "formação editorial foi realmente prática, bem como que havia feito um curso de extensão universitária em marketing na FGV, no final dos anos 80 ". ${ }^{4}$

O Sr. José Lino Fruet, também da Saraiva, era graduado em Comunicação Social, com especialização em Jornalismo. Destacou, porém, que 
para se manter atualizado, lia muito, "não só na área de Comunicação propriamente dita, mas, inclusive, na área de Pedagogia, Didática e Educação". ${ }^{5}$

O Sr. José Orlando Cunha, da Editora Lê, teve uma curta passagem pelo curso de Medicina da UFMG, mas graduou-se em Administração de Empresas. Relatou que teve a "oportunidade de fazer vários cursos paralelos à área de administração, durante todo este período de formação, que foi de junho de 1976 até os dias de hoje", ${ }^{6}$ bem como que procurava estar sempre atualizado sobre os métodos mais modernos de administração.

O Sr. João Guizzo, editor da Ática à época, informou que sua formação acadêmica era em Letras e também em Ciências Sociais, "de modo que esses cursos me deram uma base boa para o trabalho que eu faço: o curso de Letras me habilitando no trabalho com texto e o curso de Ciências Sociais porque ele dá uma base cultural ampla muito boa, ao mesmo tempo uma base teórica e uma base informativa muito ampla, muito boa, para esse tipo de trabalho" (Munakata, 1997, p. 22).

Depreende-se das informaçóes fornecidas pelos editores elencados que todos cursaram apenas a graduação, nas áreas de Letras, Administração, Comunicação e Ciências Sociais, que aparentemente são áreas heterogêneas, mas que, de certa forma, têm interfaces com o trabalho editorial.

Quanto ao itinerário profissional dos editores, o Sr. Antônio Alexandre Faccioli relatou ter iniciado seu trabalho junto à editora Saraiva há 25 anos:

Fui desenvolvendo um trabalho, assumindo maiores responsabilidades, coordenando, gerenciando e chegando a direção do departamento. Esse processo todo está muito ligado ao próprio crescimento do papel do livro didático no mercado. Então, esse boom do final dos anos sessenta exigiu o desenvolvimento de profissionais. Formação, que foi feita na prática. (...) No meu caso, especificamente, como diretor, você vai também aprimorando um conhecimento maior de mercado, de marketing e de administração. Enfim, em todos os aspectos ligados ao trabalho como diretor de departamento como um todo, e não só ao aspecto técnico do livro didático. ${ }^{7}$

Sobre seu itinerário profissional, o Sr. José Lino Fruet relatou que também havia iniciado suas atividades como copidesque, bem como que 
Estado e editoras privadas no Brasil: o papel e o perfil dos editores de livros didáticos...

(...) tinha a opção de trabalhar com fascículos, que era uma onda na época. Mas surgiu a oportunidade de eu vir para cá e aqui fiquei, percorrendo todos os graus. Copidesque, supervisor e gerente. Isto já faz 24 anos. (...) a gente procurou aperfeiçoar bastante o processo de produção editorial, que era um processo um tanto artesanal. ${ }^{8}$

O Sr. José Orlando Cunha comentou sobre sua dedicação intensiva à editora e sobre suas vinculações classistas, pois segundo o editor,

(...) o principal negócio da minha atividade sempre foi a Editora Lê, com o exercício de um trabalho em tempo integral. A Editora Lê criou, nestes últimos anos, um apêndice que é a gráfica que serve à própria Editora e serve também a outros (...). Eu já fui diretor do Sindicato Nacional dos Editores de Livros (SNEL). Eu sou diretor fundador da Associação Brasileira de Livros Didáticos (ABrelivros) e sou, atualmente, diretor suplente da Câmara Brasileira do Livro (CBL). ${ }^{?}$

O itinerário profissional do Sr. João Guizzo foi o seguinte:

Entrei via anúncio de jornal, que pedia um copy [copidesque], copy de didáticos, e como eu tinha experiência de trabalho em texto, eu era redator, então eu me candidatei e fui admitido como redator em 1975. (...) Comecei dessa forma e, dentro da Ática, logo depois de um ano de trabalho, mais ou menos, passei a coordenar uma pequena equipe de profissionais de texto - também redatores que passaram a trabalhar em texto, fazer o copy de textos didáticos. Hoje a equipe é um pouco maior, são 25 pessoas comigo. Então, eu acompanhei bastante esse crescimento da empresa - se bem que um pouco, assim, como crescimento de um filho, porque quando o filho vai crescendo, quem nota que o filho cresceu são os outros. Assim também na Ática: ela foi crescendo, crescendo, aumentando e eu aqui dentro. Lógico, de vez em quando, se eu paro para fazer um balanço, eu me dou conta desse crescimento, mas no dia-a-dia a gente não observa. (...) Eu, pessoalmente, de redator passei a assistente editorial, depois a assessor e, finalmente, a gerente que é o cargo que eu tenho hoje. (Munakata, op. cit., p. 122)

Os editores entrevistados revelaram em seus depoimentos que eram profissionais que fizeram carreira nas editoras em que trabalhavam. Carreiras longas, quase todas iniciadas na década de 1970 e que, portanto, já beiravam, naquela época, aos 30 anos de experiência no ramo editorial. 
Figura 1

(Capa da 17a edição do livro História do Brasil, de Joana Neves e Elza Nadai, publicado pela Saraiva, em 1995)

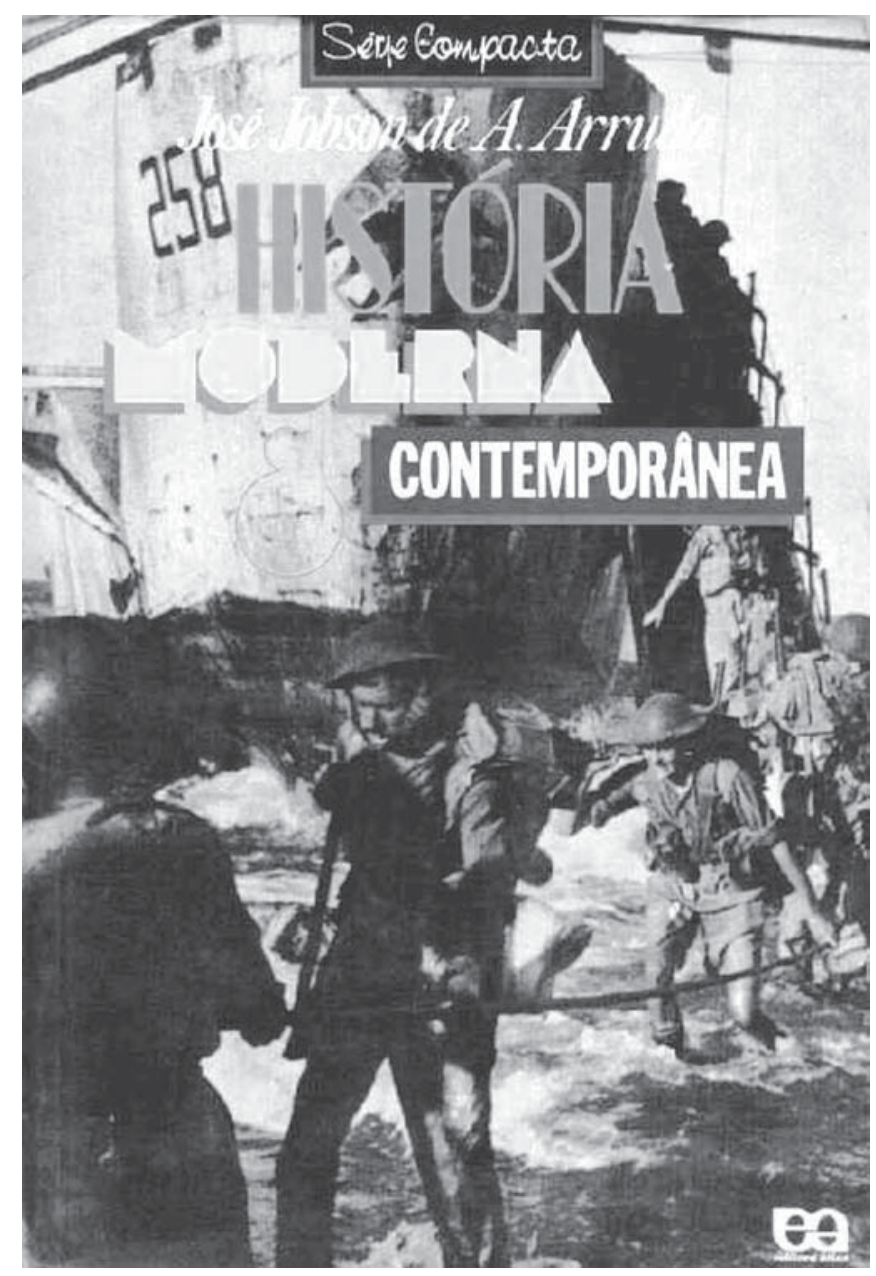

Cad. Cedes, Campinas, vol. 25, n. 67, p. 365-377, set./dez. 2005 
Estado e editoras privadas no Brasil: o papel e o perfil dos editores de livros didáticos...

Figura 2

(Capa da $1^{\text {a }}$ edição do livro História moderna e contemporânea, de José Jobson de Andrade Arruda, publicado em 1991, pela Editora Ática)

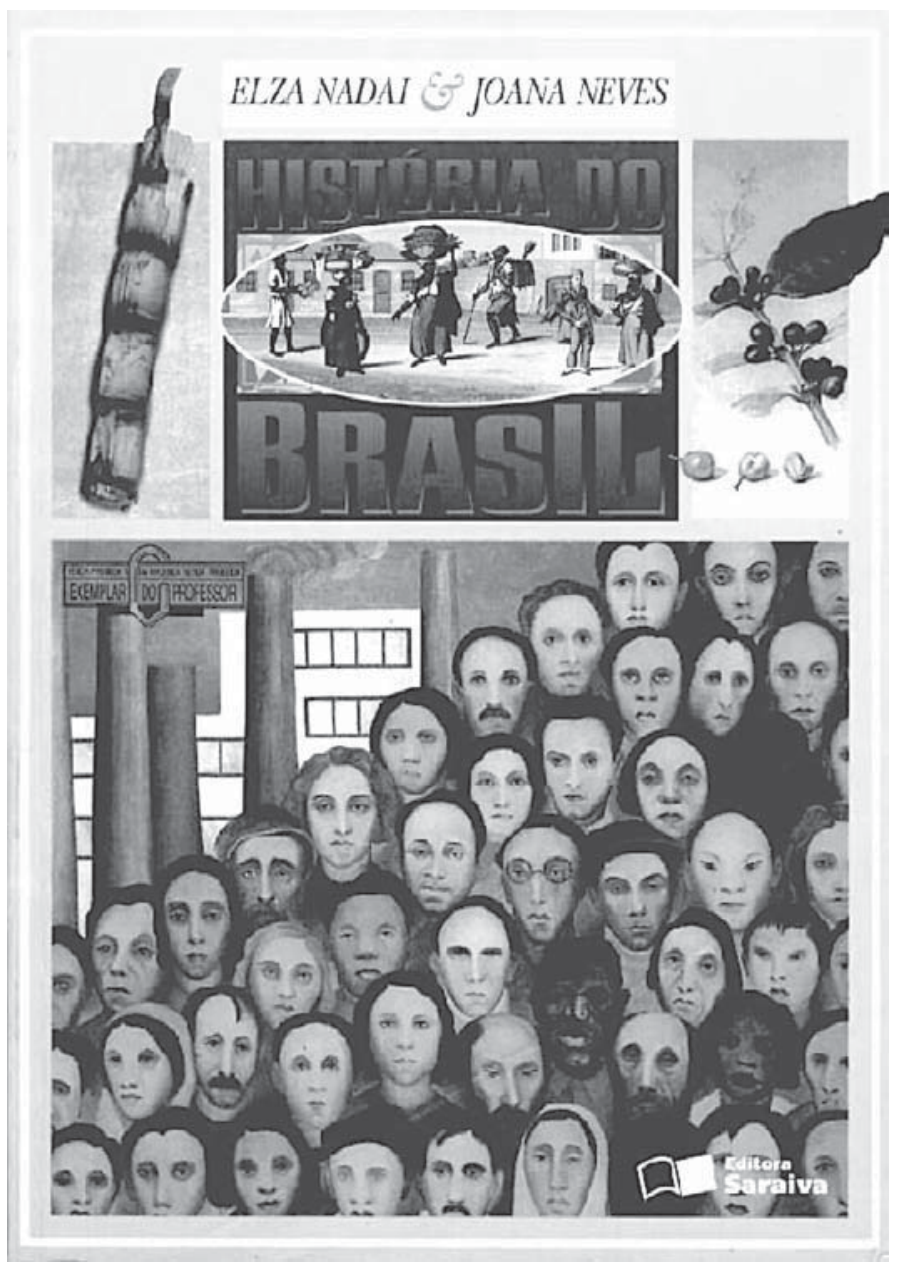


Figura 3

(Capa da 1a edição do livro Brasil: história em construção (vol. 3), de autoria de Ricardo de Moura Faria, Adhemar Martins Marques e Flávio Berutti, publicado pela Editora Lê, em 1996).

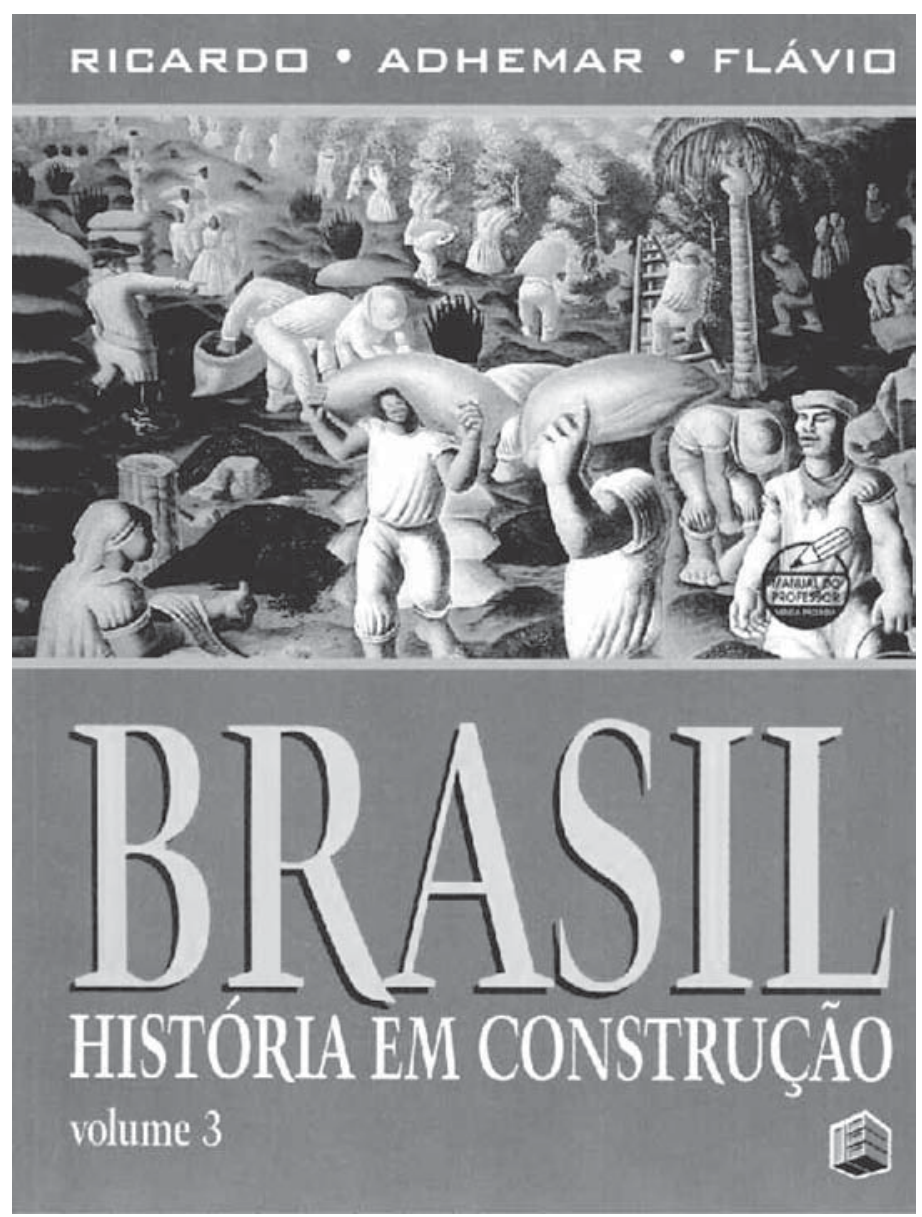

Cad. Cedes, Campinas, vol. 25, n. 67, p. 365-377, set./dez. 2005

Disponível em <http://www.cedes.unicamp.br> 
Estado e editoras privadas no Brasil: o papel e o perfil dos editores de livros didáticos...

\section{Relação dos editores com os autores}

De modo geral, os depoimentos dos editores demonstraram a existência de ótimo relacionamento profissional e pessoal com seus autores, aos quais consideravam como seus parceiros. Somavam mais de 20 anos o relacionamento estabelecido entre os editores e os autores dos livros da área de história selecionados à época das entrevistas, em $1997 .{ }^{10}$ Sendo assim, os editores forneceram informações interessantes. O Sr. José Lino Fruet informou que:

No caso da Saraiva, o autor é um parceiro. Não quer dizer que ele mande no produto, mas ele participa do produto. Nós sempre procuramos discutir, mostrar para ele, obter a aprovação dele também. Sabemos que em algumas editoras o autor não interfere muito nesse processo. Só vê o livro pronto. Existia, no passado, editoras em que o autor, inclusive, se responsabilizava pela produção dos desenhos. Ele é quem tinha que providenciar. A tendência, (...) nas editoras em geral e na Saraiva especificamente, é do autor ter voz ativa. É claro que às vezes a visão dele é limitada, tal como a postura pedagógica e técnica. Essa é uma das razões dos pareceristas de fora. (...) Acho que tem que haver a contribuição de todos para alargar o espectro de aceitação da obra em todos os sentidos. (...) Há autores que não querem se envolver muito. A gente faz com que eles se envolvam, pela questão da parceria. Pelo menos ver e dar a sua opinião. Há outros que querem ser extremamente deterministas. (...) É claro que temos que adequar. Isso é uma discussão grave também que existe. (...) Com os ilustradores, por exemplo, muitos deles se acham artistas e querem fazer a obra deles. Eles não se viam inseridos em um processo industrial, pedagógico etc. Eles têm que adequar a atividade deles àquela proposta. (...) Ele sempre tem algum compromisso e ainda está inserido num processo pedagógico. Não é só o industrial. ${ }^{11}$

O Sr. José Orlando Cunha, da Editora Lê, por seu turno, abordou a temática de seu relacionamento com os autores da área de História vinculados a sua editora, informado que:

Essas parcerias - nós entendemos isso dentro da empresa - têm que ser um trio. Ele tem que ser muito forte e fortalecido o tempo todo: o autor, o editor e o comercial. (...) Obviamente que existe um diálogo muito bom, muito grande nas propostas a fazer para eles. Nós temos que ouvir deles o desenvolvimento do original, o acompanhamento é deles em nossa área de produção, quer dizer, tem que haver um entendimento muito grande entre autor e editor através da produção, para sair um bom produto, que ve- 
nha a satisfazer o autor, o público e a empresa comercialmente. O importante é ter mais de um autor em uma obra porque é mais de uma cabeça, é mais uma experiência e é muito importante também sempre que o autor, que escreve para a Editora Lê, esteja intimamente ligado com a sala de aula. Isto é muito importante para nós. ${ }^{12}$

Percebe-se, desse modo, que o autor era considerado pelos editores um parceiro, mas um parceiro que não devia e nem podia fugir aos limites que o mercado consumidor e a política editorial estipulavam. As coleções didáticas, empreendimentos altamente dispendiosos, não davam margem a muitas inovaçoes. Os editores destacaram, inclusive, problemas que, vez por outra, enfrentavam com o setor de artes que tinha dificuldades em aceitar os limites impostos pelo mercado para a edição dos livros escolares.

É interessante observar, no entanto, a preocupação do Sr. José Orlando Cunha em ter mais de um autor para suas coleções e que esses autores tenham uma vinculação com a sala de aula. Provavelmente, essa preocupação esteja vinculada a necessidades intimamente ligadas à capacidade dos autores estarem modernizando suas coleçôes constantemente, mantendo-as sempre afinadas com a linguagem dos alunos; à disponibilidade dos autores para realizarem essas modernizações, lançando coleçôes novas em um ritmo veloz e, sobretudo, participando das fortes estratégias de divulgação da editora.

\section{Considerações finais}

Partiu-se da constatação de que as grandes editoras do final da década de 1990 tinham na produção de livros didáticos seu suporte comercial, tendo sido beneficiadas pelo boom editorial da década de 1970, quando foi possível perceber a passagem da produção quase artesanal presente na realidade brasileira até a década de 1960 para a formação de uma poderosa indústria editorial.

Quanto aos editores entrevistados, há muito em comum entre eles, seja no aspecto relacionado à formação acadêmica ou mesmo ao itinerário profissional, já que eram oriundos da área de Humanas, especialmente do campo das letras e da comunicação, sendo apenas um deles oriundo da área de administração de empresas, o que os diferencia do perfil dos editores norte-americanos. Além disso, foi possível constatar que todos tinham carreiras longas nas editoras em que se encontravam no final da década de 1990. 
Estado e editoras privadas no Brasil: o papel e o perfil dos editores de livros didáticos...

Depreende-se ainda dos depoimentos dos editores que os autores eram considerados parceiros. Porém, um parceiro com sua ação cada vez mais condicionada à realidade que o mercado consumidor e a política editorial impunham.

Em síntese, pôde-se perceber que ao mesmo tempo em que se operava a passagem de uma forma de produção quase artesanal para uma produção industrial na maior parte das editoras, vivenciou-se na área de história um processo de melhoria da qualidade tanto dos conteúdos, mais críticos e completos, quanto da edição, em quatro cores e com a utilização de papel de alta qualidade, o que significava a disponibilização de um material mais adequado para a população, seja por meio da distribuição realizada pelo governo federal, seja por meio da aquisição nas livrarias.

Recebido em maio de 2005 e aprovado em setembro de 2005.

\section{Notas}

1. Ver a esse respeito Oliveira et al. (1984, p. 83-110).

2. Antônio Alexandra Faccioli e José Lino Fruet. Depoimento (1997, p. 18-20).

3. Idem, ibid., p. 23.

4. Idem, ibid., p. 1.

5. Idem, ibid.

6. José Orlando P. da Cunha. Depoimento (1997, p. 106).

7. Antônio Alexandra Faccioli e José Lino Fruet. Depoimento (1997, p. 2).

8. Idem, ibid.

9. José Orlando P. da Cunha Depoimento (1997, p. 106-107).

10. Os autores em questão eram as professoras Joana Neves e Elza Nadai (Editora Saraiva), o professor Ricardo Moura Faria (Editora Lê) e o professor José Jobson de Andrade Arruda (Editora Ática).

11. Antônio Alexandra Faccioli e José Lino Fruet. Depoimento (1997, p. 28-29).

12. José Orlando P. da Cunha. Depoimento (1997, p. 111).

\section{Referências bibliográficas}

APPLE, M.W. Trabalho docente e textos: economia política das relações de classe e de gênero em educação. Porto Alegre: Artes Médicas, 1995. p. 94. 
CARVAlHO, L.I. A distribuição e circulação de livros nas escolas paulistas. 1991. Dissertação (Mestrado) - Pontifícia Universidade Católica de São Paulo, São Paulo. p. 16.

MUNAKATA, K. Produzindo livros didáticos e paradidáticos. 1997. Tese (Doutorado) - Pontifícia Universidade Católica de São Paulo, São Paulo. p. 20.

OliveirA, J.B.A. et al. A politica do livro didático. São Paulo: Summus; Campinas: UNICAMP, 1984. p. 83-110. 